\title{
TOPOLOGY AND SHAPE OPTIMIZATION OF A MOUNT LINK CONSIDERING LOCAL MICROSTRUCTURE-DEPENDENT FATIGUE PROPERTIES OBTAINED FROM FORMING SIMULATIONS
}

\author{
H. Maderbacher ${ }^{1}$, C. Wagner $^{1}$, B. Oberwinkler ${ }^{2}$, H.-P. Gänser ${ }^{3}$, M. Riedler ${ }^{2}$ \\ ${ }^{1}$ Chair of Mechanical Engineering, Montanuniversität Leoben, Franz-Josef-Straße 18, \\ 8700 Leoben, Austria \\ ${ }^{2}$ Böhler Schmiedetechnik GmbH\&Co KG, Mariazellerstraße 25, 8605 Kapfenberg, Austria \\ ${ }^{3}$ Materials Center Leoben Forschung GmbH, Roseggerstraße 12, 8700 Leoben, Austria
}

\begin{abstract}
In times of increasing costs for energy and natural resources together with the aim of getting environmental pollution under control, light weight design is of paramount importance today. Light weight design always goes along with the best possible knowledge of the used material's behavior, the influencing boundary and environmental conditions as well as the loading in service to ensure the component's fitness for purpose. As an example of lightweight design the dimensioning and fatigue lifetime evaluation of a hot forged Ti-6-4 aerospace engine mount link shall be considered in what follows. In the first step, a topology and shape optimization is used for stress minimization. Two design proposals are retained; one having maximum fatigue life, the other having least weight. In the next step, the optimized geometries as well as the original mount link are analyzed in a finite element (FE) simulation to get the stress results in each node. The fatigue lifetime estimation is performed by means of a special purpose post-processor taking into account the influence of the local microstructure as obtained from the forming simulation. These data are used to compare weight and fatigue lifetime of the original and the optimized geometries. Finally, the optimized components are manufactured and tested to verify the computational method.
\end{abstract}

Keywords: Topology optimization, shape optimization, fatigue, Ti-6-4

\section{INTRODUCTION}

Under the paradigms of lightweight design and damage tolerance, the number of demands to be fulfilled simultaneously in component design is constantly increasing. For example, if an optimized aircraft component is regarded, the component should be lightweight to save energy costs in the operation; it should have a high strength and should be cost effective in manufacturing; it should be corrosion resistant, have a low density, but should have a large static and fatigue strength simultaneously. Large fracture toughness and a high crack growth 
threshold are likewise indispensable. A component's strength and weight, however, do not only depend on material strength and density, but also on its geometrical design; therefore the geometry has to be adapted, by removing superfluous material, such that the material's maximum load carrying capacity is used at each material point in the remaining load-carrying cross section. In the present case a hot forged Ti-6-4 aircraft engine mount shall be investigated. Ti-6-4 fulfills many of the above material requirements and is not subject of optimization in this work. Rather, we are concerned with optimizing the geometrical design of the engine mount by means of topology and shape optimization in a way that weight and/or fatigue lifetime are optimized. The fatigue lifetime calculation consists of a finite element stress analysis followed by post-processing by a special purpose software [2] in which a complex fatigue model [4] for Ti-6-4 has been implemented; the model allows an assessment of cumulative fatigue damage following the Miner rule as well as the computation of admissible flaw sizes, i.e., a damage tolerance assessment, under a given load spectrum. In order to verify the entire simulation chain, several topology-optimized components have been manufactured and tested at different loads; the numerical predictions are in good accordance with the experiments.

\section{INVESTIGATED COMPONENT}

As already mentioned, in this work the application of topology and shape optimization followed by fatigue life prediction for an aircraft engine mount link is discussed. The mount link is made of Ti-6-4 and the raw geometry is produced by hot forging before the final geometry is achieved by machining. The definition of forces is in accordance with FAR Subpart C CS-25 [1], where just the largest loads in the particular direction are considered amongst the numerous listed ones. These forces are the engine thrust, the vertical acceleration forces and the lateral wind forces, and can be estimated with 60,62 and $0.5 \mathrm{kN}$, respectively, for an engine with the assumed key data listed in Table 1 [6]. The schematic location of the engine mount and the loading directions of the individual forces are shown in Figure 1. The load spectrum, consisting of 5000 cycles, is similar in shape and fullness to the standard spectrum TWIST for aircraft wings [5]; Table 2 shows the multiplication factors for the mean stress $f_{m}$ and for the amplitude stress $f_{a}$, whereas Table 3 provides some background information on the load distribution during a typical flight. A reference engine mount was designed by an engineering office [3]; this original mount is the starting point for the topology and shape optimization, and serves as a reference for weight and lifetime comparisons.

Table 1: Engine key data

\begin{tabular}{ll}
\hline Engine property & Value \\
\hline Thrust & $\sim 60 \mathrm{kN}$ \\
Fan diameter & $\sim 1,4 \mathrm{~m}$ \\
Length & $\sim 2,3 \mathrm{~m}$ \\
Dry mass & $\sim 1.700 \mathrm{~kg}$ \\
\hline
\end{tabular}




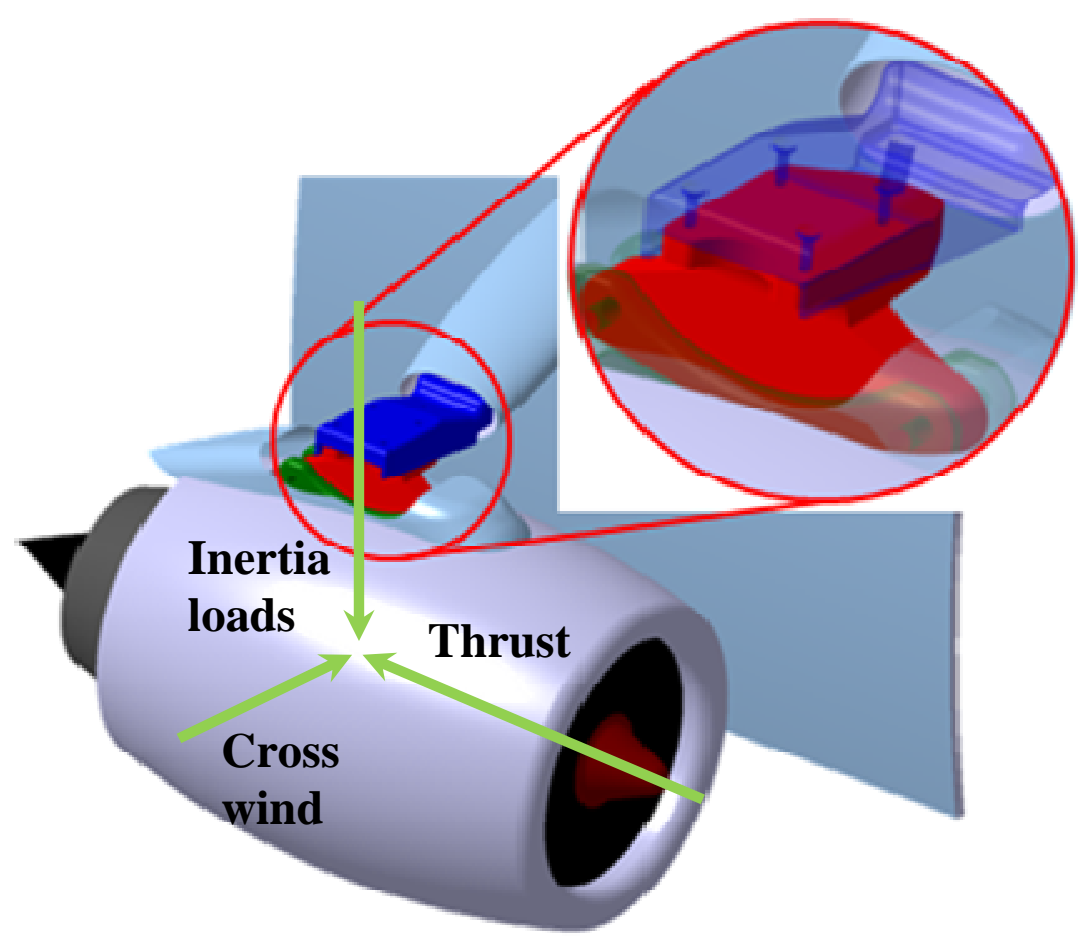

Figure 1: Engine mount location with load directions

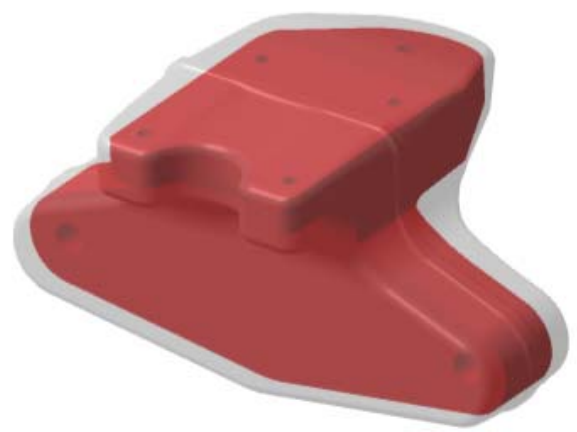

Figure 2: Basic geometry for the topology optimization; forging without forging skin including connection bores

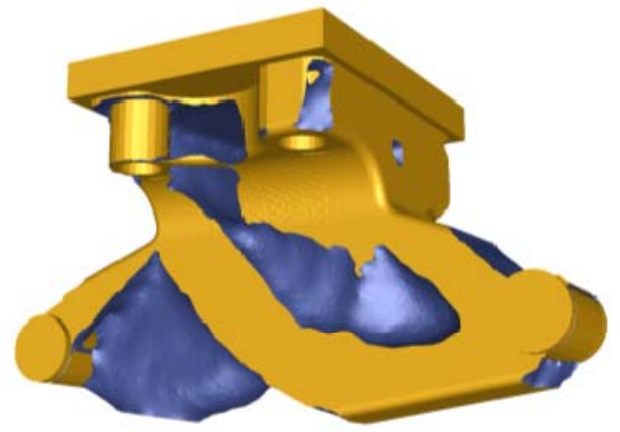

Figure 3: Result of topology optimization using Tosca $^{\mathrm{TM}}$ - minimized strain energy density, weight reduction by $40 \%$ 
Table 2: Load spectrum for mean stresses and amplitude stresses

\begin{tabular}{|c|c|c|c|c|c|c|c|}
\hline & \multicolumn{2}{|c|}{ Thrust } & \multicolumn{2}{|c|}{ Inertia loads } & \multicolumn{2}{|c|}{ Cross wind } & \multirow[t]{2}{*}{ LC } \\
\hline & $f_{a}$ & $\mathrm{f}_{\mathrm{m}}$ & $f_{a}$ & $\mathrm{f}_{\mathrm{m}}$ & $\mathrm{f}_{\mathrm{a}}$ & $\mathrm{f}_{\mathrm{m}}$ & \\
\hline \multirow{3}{*}{ 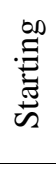 } & 0,4 & 0,6 & 0,125 & 0,125 & 0,5 & 0,5 & 1 \\
\hline & 0,4 & 0,6 & 0,5 & 0,5 & 0,5 & 0,5 & 2 \\
\hline & 0,2 & 0,6 & 0,25 & 0 & 0,5 & 0,5 & 4 \\
\hline \multirow{10}{*}{ 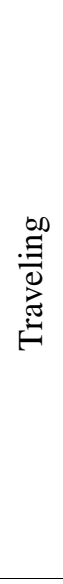 } & 0,4 & 0,6 & 0,5 & 0,5 & 0,5 & 0,5 & 1 \\
\hline & 0,4 & 0,6 & 0,35 & 0,35 & 0,5 & 0,5 & 4 \\
\hline & 0,4 & 0,6 & 0,35 & 0,25 & 0,5 & 0,5 & 7 \\
\hline & 0,4 & 0,6 & 0,32 & 0,25 & 0,5 & 0,5 & 81 \\
\hline & 0,4 & 0,6 & 0,32 & 0,25 & 0,75 & 0,75 & 107 \\
\hline & 0,2 & 0,6 & 0,32 & 0,25 & 0,75 & 0,75 & 12 \\
\hline & 0,2 & 0,6 & 0,25 & 0,25 & 0,75 & 0,75 & 688 \\
\hline & 0 & 0,6 & 0,25 & 0,25 & 0,75 & 0,75 & 3993 \\
\hline & 0 & 0,6 & 0,2 & 0,25 & 0,5 & 0,5 & 93 \\
\hline & 0 & 0,6 & 0,1 & 0,25 & 0,5 & 0,5 & 4 \\
\hline \multirow{3}{*}{ } & 0,4 & 0,6 & 0,5 & 0,5 & 0,5 & 0,5 & 1 \\
\hline & 0 & 0,1 & 0,5 & 0,25 & 0,5 & 0,5 & 1 \\
\hline & 0 & $-0,13$ & 0,25 & 0,125 & 0,5 & 0,5 & 1 \\
\hline
\end{tabular}

Table 3: Description of the used load spectrum

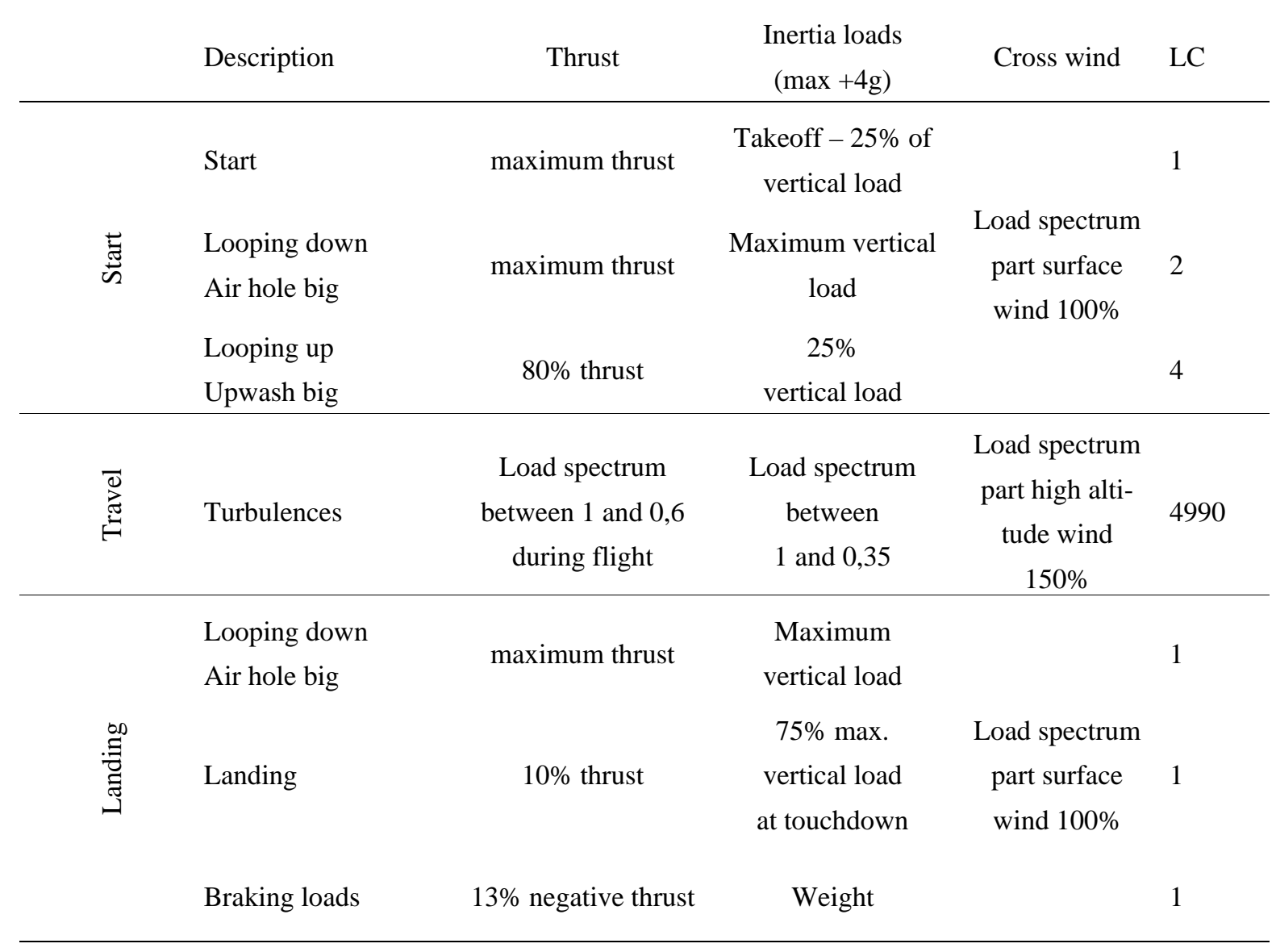




\section{TOPOLOGY AND SHAPE OPTIMIZATION}

To obtain an optimal geometry with respect to maximum stiffness and durability while minimizing weight a topology optimization for weight loss with subsequent shape optimization is conducted. The starting point is the forging blank minus a forging skin of 3mm under consideration of the positions for connecting bores and connecting surfaces to neighboring components. With this basic geometry, shown in Figure 2, the optimization cycle is started. To this purpose, a finite element model for the commercial FE software package Abaqus ${ }^{\mathrm{TM}}$ is created that is intended to reflect reality with as little effort as possible. The engine mount is meshed with second-order tetrahedra, has a linear elastic material behavior, is fixed with four elastically pre-stressed screws to a steel plate, and the loads are transferred from the engine center of gravity to the bolt bosses by means of beam elements. The finite element simulation is linked with the topology and shape optimization tool Tosca ${ }^{\mathrm{TM}}$ to obtain a geometry with maximum rigidity at low weight. For the topology optimization, a design area is defined where the material density may be varied depending on the computed strain energy density, which is defined as design response. The areas around the bores, which are essential for connecting to the neighboring components, are defined as invariant. The result of the topology optimization for maximum strain energy density gives a weight reduction of $40 \%$ and can be seen in Figure 3. Following the topology optimization, a shape optimization is performed to homogenize stresses at critical points by shifting nodes; Figure 5 shows the ellipsoidal rounding of the initially relatively sharp notch (see Figure 4). In a similar manner, two optimized geometries are obtained for two different objective functions and constraints: the first one with maximum fatigue endurance while maintaining a weight that is less or equal to that of the reference component, and the second one that offers at least the same fatigue resistance as the reference component but is as light as possible. The optimization results are slightly corrected in order to obtain machinable components (Figure 7 and Figure 8). Comparison with the reference geometry from Figure 6 gives the following results: the maximum lifetime version (see Figure 7 and Table 4) has 10 times the service life even though it has a more than $10 \%$ lower weight than the reference geometry; for a detailed description of the lifetime computations, see Section 5 . The extreme lightweight version shows a $40 \%$ reduction in weight even though its lifetime is twice the lifetime of the reference geometry (see Figure 8 and Table 4).

Table 4: Comparison of the optimization results with the reference geometry

\begin{tabular}{lccc}
\hline & original & optimized fatigue life & optimized weight \\
\hline relative weight & $100 \%$ & $91 \%$ & $69 \%$ \\
relative max equiv stress & $100 \%$ & $54 \%$ & $75 \%$ \\
relative damage & $100 \%$ & $9 \%$ & $62 \%$ \\
\hline
\end{tabular}




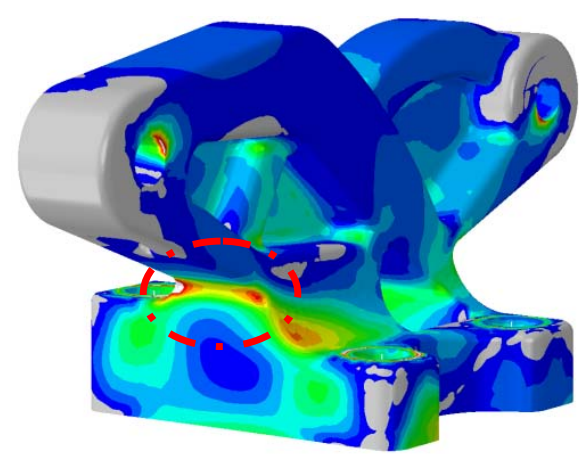

Figure 4: Stress concentrations in the enginge mount designed in accordance to the Tosca ${ }^{\mathrm{TM}}$ topology optimization proposal

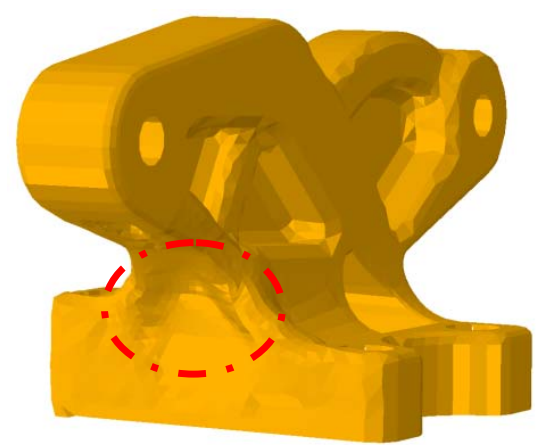

Figure 5: Ellipsoidal rounding of the initially relatively sharp notch as a result of the Tosca ${ }^{\mathrm{TM}}$ shape optimization

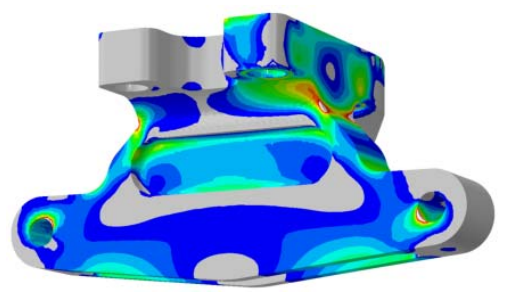

Figure 6: Original reference geometry

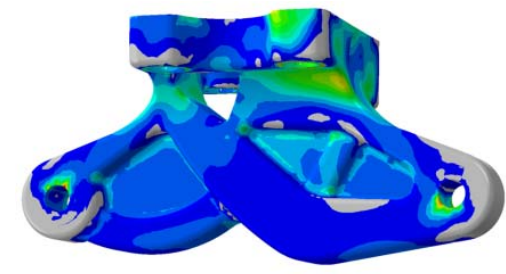

Figure 7: Geometry with optimized fatigue life

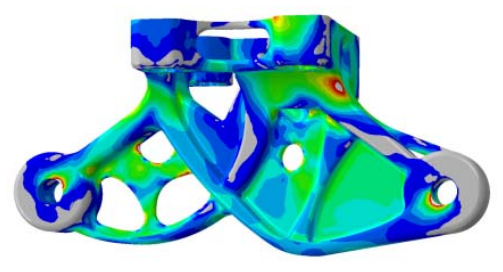

Figure 8: Geometry with optimized weight

\section{COMPONENT TESTS}

To verify the performed life calculation and the associated FE simulation, components very similar to the geometry in Figure 7 are manufactured from raw forgings, see Figure 13. These components are tested under cyclic loading. The component tests are performed on a servohydraulic test rig at IABG, Munich. The test rig can be seen in Figure 9. As in the simulation, the engine mount is screwed with 4 screws with predefined prestressing onto a steel plate. The thrust, inertia, and cross wind forces forces are introduced via three orthogonal hydraulic cylinders at the distance of the engine's center of gravity, and transmitted into the bolt bosses via a specially designed handle. In addition, strain gauges are placed at specific points on the component in order to verify the accuracy of the FE simulation. To reduce the duration of the experiment, not the entire load spectrum is used, but only the starting and landing part, where the biggest damage is expected. First, the components are tested with the forces and spectra detailed above; in a second step, the forces are reduced by $20 \%$ while the spectra keep unchanged. The cycles to failure for these tests are shown in Figure 10. Figure 11 shows the component just before failure occurs, Figure 12 after failure. To enable better visibility of the cracks, the components were sprayed with zinc oxide. In the next section, these findings with respect to location of failure and cycles to failure will be compared with the simulation results. 

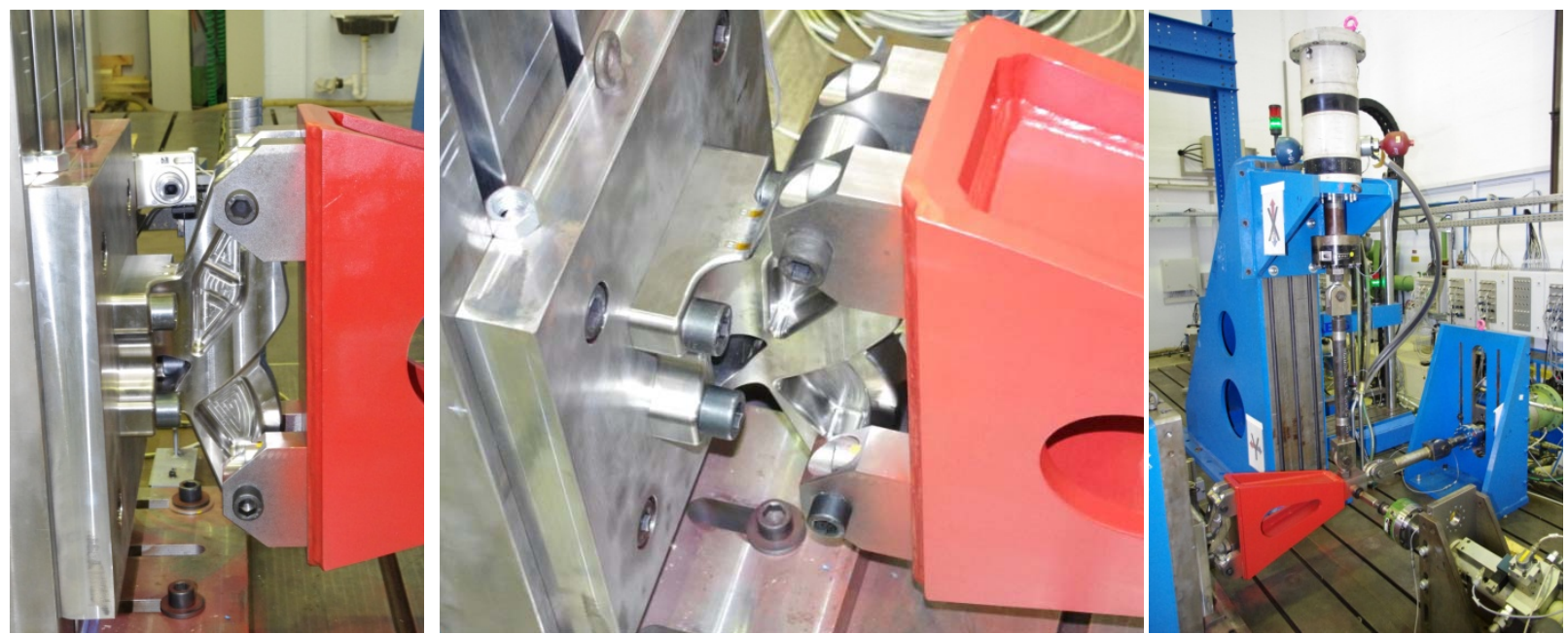

Figure 9: Setup of the component fatigue test

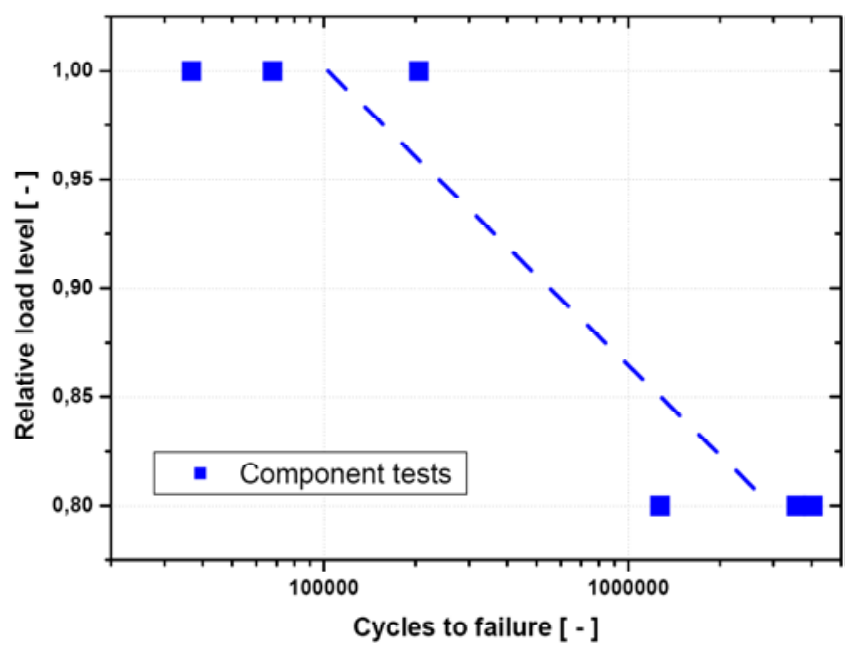

Figure 10: Results of the component fatigue tests at two different load levels

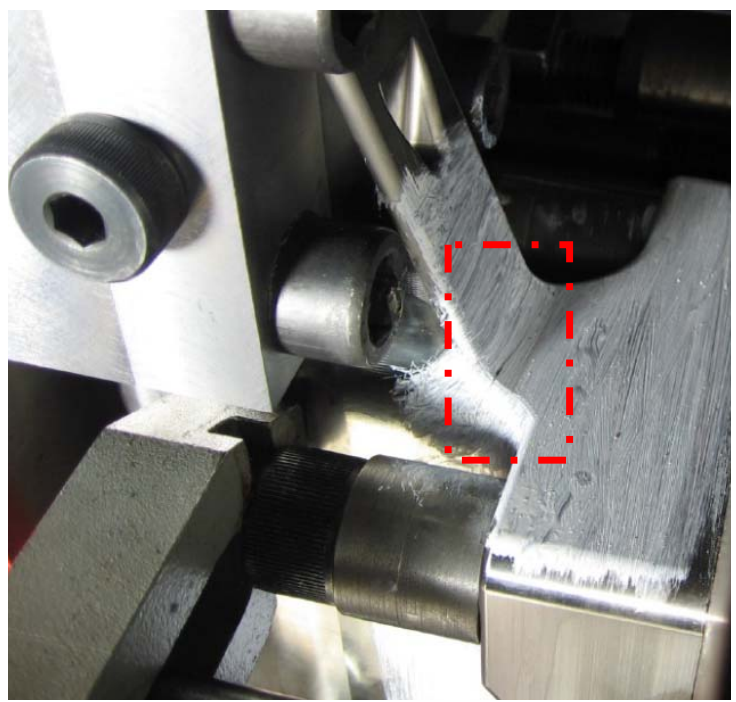

Figure 11: Component coated with zinc oxide 200 cycles before ultimate failure

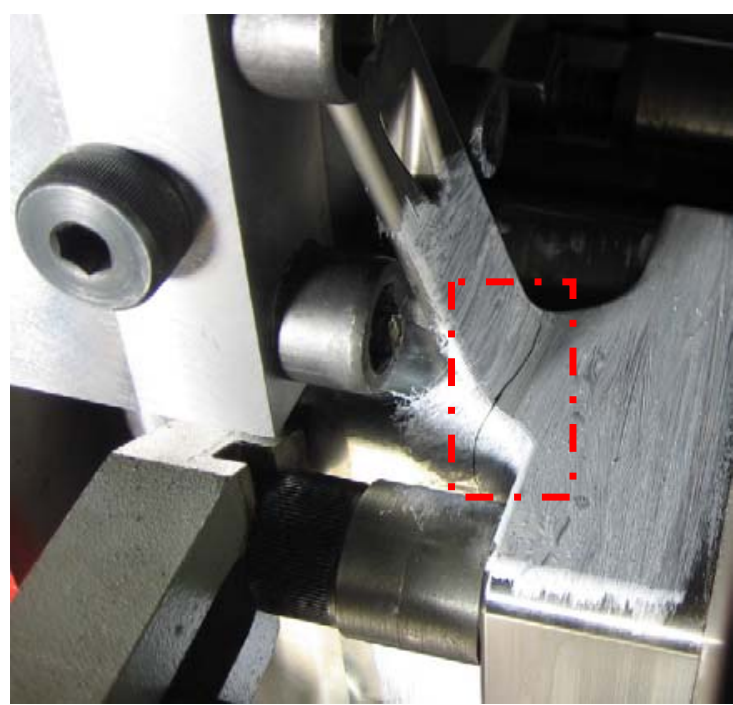

Figure 12: Component coated with zinc oxide at ultimate failure 

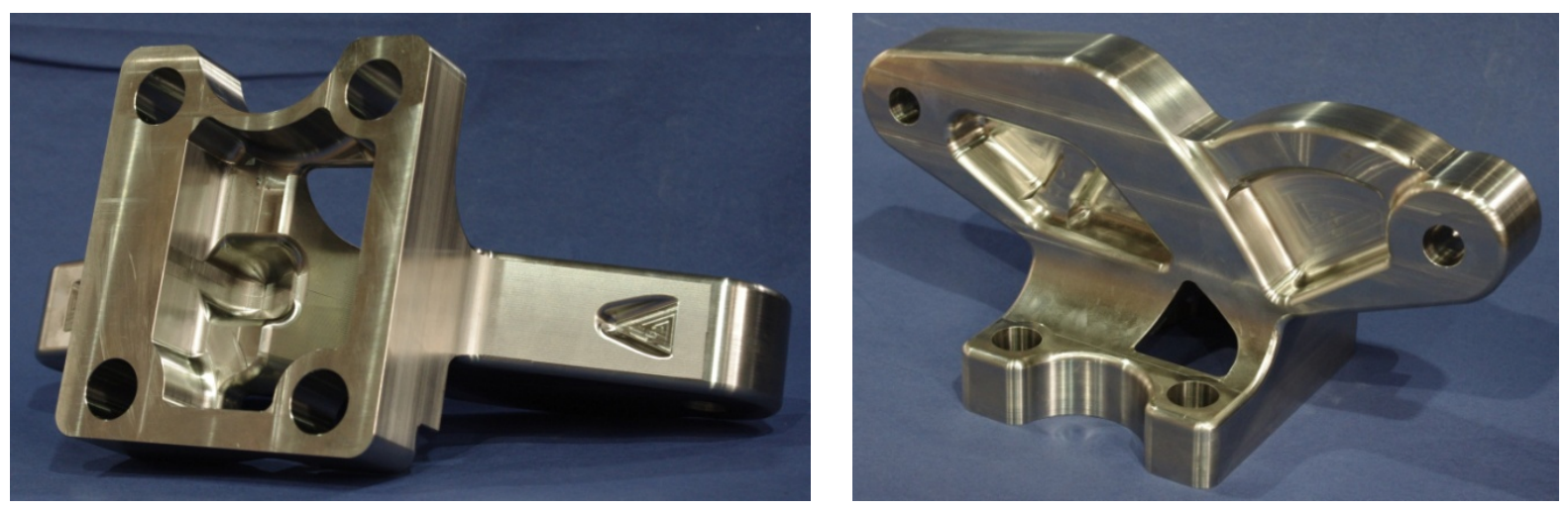

Figure 13: Machined engine mount for the component tests

\section{FATIGUE ENDURANCE CALCULATION}

As mentioned earlier, an accurate fatigue life model for the used material along with precise knowledge of emerging forces, the load spectrum and the present environmental conditions is essential for a lifetime assessment. The fatigue model used for Ti-6-4 does not only take into account the local microstructure resulting from the forging process and heat treatment, but also the beneficial effects of surface treatments such as shot peening, the stress gradient, the mean and amplitude stress and the operating temperature [4], as depicted in Figure 14. This model is implemented into the fatigue postprocessor BoFaP [2] (Boehler Fatigue Postprocessor), which accesses directly the results of the Abaqus ${ }^{\mathrm{TM}}$ stress analysis and the microstructural data of a Deform ${ }^{\mathrm{TM}}$ forging simulation; damage and critical crack sizes are estimated from the calculated local stresses, local microstructural parameters, and the given load spectrum, as detailed below. The stress differences between simulation results and strain gauge measurements on the component are well below $10 \%$, so the simulation is considered to be representative of the experiment. After the stresses are calculated for the maximum force in any direction, the postprocessor combines the stress tensors of the three loading directions for each load combination as it is defined by the mean stress and amplitude stress spectrum. From the resulting mean stress and stress amplitude now damage is calculated for each load case. Finally, using linear damage accumulation, the total damage is calculated. The necessary basic equations of the damage calculation can be seen from equation (1) to equation (11). All components of the stress tensors $A, B$ and $C$, which result from the maximum force for each direction, are multiplied with the amplitude factors $f_{\mathrm{a} * \mathrm{k}}$ and the mean stress factors $f_{\mathrm{m} * \mathrm{k}}$ (equation (1) - (3) and equation (6) - (8); * denotes $A, B$, or $C$, respectively). In the next step, a total mean stress $S_{\mathrm{m} k}$ and a total amplitude stress $S_{\mathrm{a} k}$ as resulting stress from all loading directions is calculated as shown by equation (9) and equation (4). Since it has been found that the equivalent von Mises stress proves to be very suitable for the material Ti-6-4 with respect to fatigue loading, now an equivalent mean stress $\left|S_{\mathrm{mk}}\right|$ and an equivalent amplitude stress $\left|S_{\mathrm{ak}}\right|$ are calculated (equation (10) and equation (5)). Using this mean stress and amplitude stress the postprocessor estimates the damage for one load level $k$ of the load spectrum. The total damage $D$ is calculated according to Miner's rule, equation (11), as the sum of the partial damage of each load combination of the spectrum, where the endurable number of cycles $N\left(\left|S_{\mathrm{ak}}\right|,\left|S_{\mathrm{mk}}\right|\right)$ at load level $k$ comes from the microstructure-dependent fatigue 


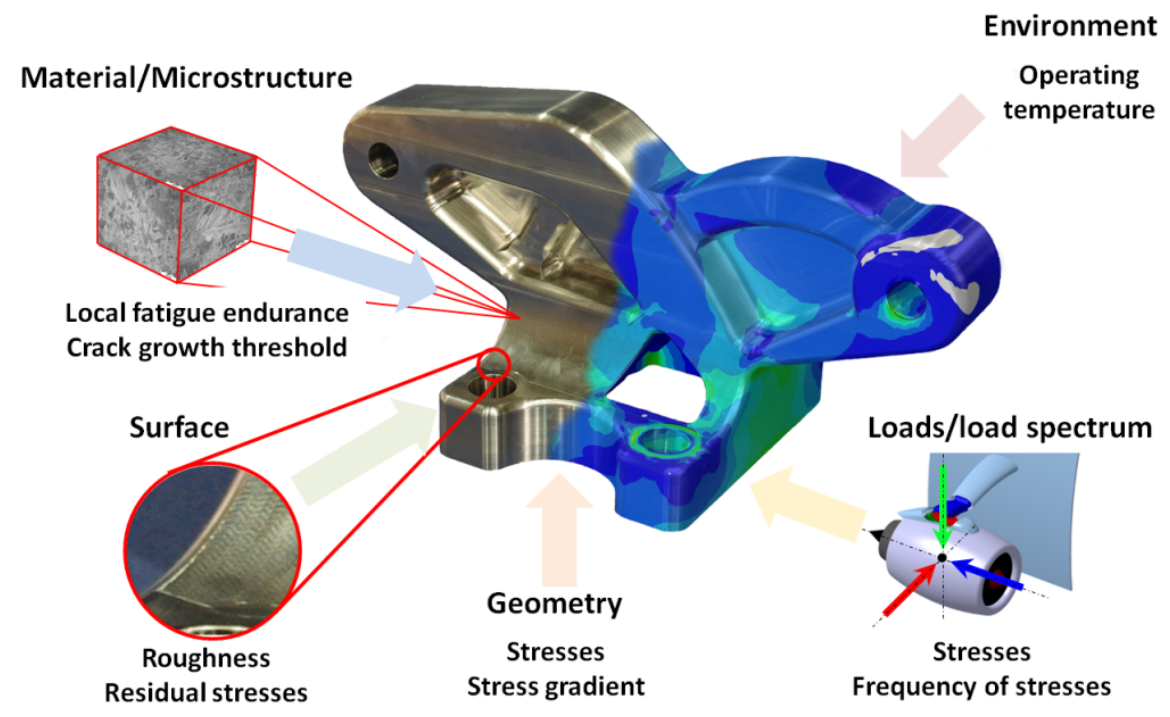

Figure 14: Considered influences in the fatigue calculation

model described in detail in [4]. The comparison of the component tests with the calculated endurance line is depicted in Figure 15 and shows very good agreement.

Stress amplitude

$$
\begin{gathered}
\underline{\underline{S}}_{\mathrm{fAak}}=f_{\mathrm{aAk} k} \underline{\underline{A}} \\
\underline{\underline{S}}_{\mathrm{fBak}}=f_{\mathrm{aBk}} \underline{\underline{B}} \\
\underline{\underline{S}}_{\mathrm{fCak}}=f_{\mathrm{aCk}} \underline{\underline{C}} \\
\underline{\underline{S}}_{\mathrm{a} k}=\underline{\underline{S}}_{\mathrm{fAak}}+\underline{\underline{S}}_{\mathrm{fBak}}+\underline{\underline{S}}_{\mathrm{fCak}}
\end{gathered}
$$$$
\left|S_{\mathrm{a} k}\right|=\sqrt{\frac{1}{2}\left[\left(S_{\mathrm{a} k 11}-S_{\mathrm{ak} 22}\right)^{2}+\left(S_{\mathrm{a} k 22}-S_{\mathrm{ak} 33}\right)^{2}+\left(S_{\mathrm{ak} 33}-S_{\mathrm{ak} 11}\right)^{2}+6\left(S_{\mathrm{ak} 12}^{2}+S_{\mathrm{ak} 23}^{2}+S_{\mathrm{ak} 31}^{2}\right)\right]}
$$

Mean stress

$$
\begin{gathered}
\underline{\underline{S}}_{\mathrm{fAmk}}=f_{\mathrm{mAk}} \underline{\underline{A}} \\
\underline{\underline{S}}_{\mathrm{fBm} k}=f_{\mathrm{mBk}} \underline{\underline{B}} \\
\underline{\underline{S}}_{\mathrm{fCmk}}=f_{\mathrm{mCk} k} \underline{\underline{C}} \\
\underline{\underline{S}}_{\mathrm{m} k}=\underline{\underline{S}}_{\mathrm{fAmk}}+\underline{\underline{S}}_{\mathrm{fBm} k}+\underline{\underline{S}}_{\mathrm{fCm} k}
\end{gathered}
$$

$$
\left.\left|S_{\mathrm{m} k}\right|=\sqrt{\frac{1}{2}\left[\left(S_{\mathrm{m} k 11}-S_{\mathrm{m} k 22}\right)^{2}+\left(S_{\mathrm{m} k 22}-S_{\mathrm{m} k 33}\right)^{2}+\left(S_{\mathrm{m} k 33}-S_{\mathrm{m} k 11}\right)^{2}+6\left(S_{\mathrm{m} k 12}^{2}+S_{\mathrm{m} k 23}^{2}+S_{\mathrm{m} k 31}^{2}\right)\right.}\right]
$$


Damage accumulation $\quad D=\sum_{k} \frac{n_{k}}{N_{k}\left(\left|S_{\mathrm{a} k}\right|,\left|S_{\mathrm{m} k}\right|\right)}$

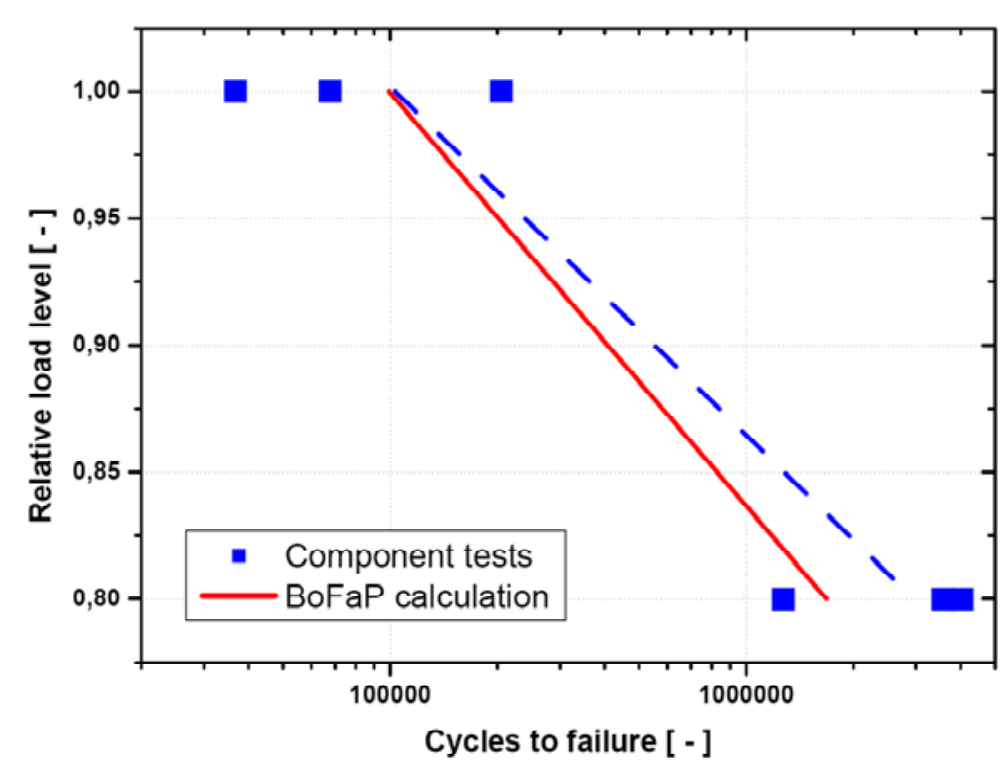

Figure 15: Comparison of component test results with calculated fatigue strength using BoFaP

\section{CONCLUSION}

An integrated simulation chain for hot-forged titanium aircraft components has been created which includes topology and shape optimization and fatigue calculation. The methods are demonstrated and validated on an aircraft engine mount made of Ti-6-4. Topology and shape optimization are used to generate either most lightweight or optimally fatigue-resistant geometries. The component lifetime is calculated using a special purpose postprocessor that takes into account the local microstructure from the forming simulation. To verify the model quality of the FEM simulation the calculated stresses are compared with the actual stresses at the machined component with strain gauge measurements. To verify the postprocessor and the microstructure-dependent lifetime model for Ti-6-4, component tests of the optimized component are conducted. The calculated fatigue lifetimes are in good agreement with the experimental results.

\section{Acknowledgements}

Financial support by the Austrian Federal Government and the Styrian Provincial Government, represented by Österreichische Forschungsförderungsgesellschaft mbH and Steirische Wirtschaftsförderungsgesellschaft $\mathrm{mbH}$, within the research activities of the K2 Competence Centre on "Integrated Research in Materials, Processing and Product Engineering”, operated by the Materials Center Leoben Forschung GmbH under the frame of the Austrian COMET Competence Centre Programme, is gratefully acknowledged. 


\section{REFERENCES}

[1] European Aviation Security Agency, Certification Specifications for Large Aeroplanes (CS-25), Subpart C Amendment 5, 2008

[2] http://www.techcomp.at

[3] May S., Titanium Fitting investigation, Report Nr. CIV09/077/01, Stainz, October 2009

[4] Oberwinkler B., Fatigue-Proof and Damage Tolerant Lightweight Design of Ti-6Al-4V Forgings, Doctoral Thesis, Montanuniversität Leoben, April 2010

[5] Schütz D.; Lowak H.; de Jonge J.B.; Schijve J.: Standardisierter EinzelflugBelastungsablauf für Schwingfestigkeitsversuche an Tragflächenbauteilen von Transportflugzeugen. LBF-Bericht Nr. FB-106 (1973)

[6] Wagner C.: Konstruktion und Optimierung einer Flugzeug-Triebwerksaufhängung (Design and optimization of an aircraft engine mount link), Project Work Report, Montanuniversität Leoben, February 2012 